\title{
Review
}

\section{Telerehabilitation-A Viable Option for the Recovery of Post-Stroke Patients}

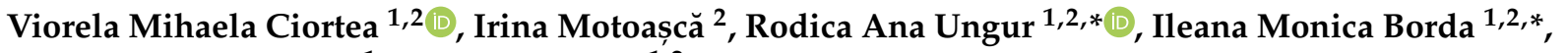 \\ Alina Deniza Ciubean ${ }^{1}$ and Laszlo Irsay ${ }^{1,2}$
}

1 Department of Rehabilitation, "Iuliu Hatieganu" University of Medicine and Pharmacy, 400012 Cluj-Napoca, Romania; viorela.ciortea@yahoo.com (V.M.C.); alina.deniza.ciubean@gmail.com (A.D.C.); irsaylaszlo@gmail.com (L.I.)

2 Clinical Rehabilitation Hospital, 400347 Cluj-Napoca, Romania; motoascairina@gmail.com

* Correspondence: ungurmed@yahoo.com (R.A.U.); monicampop@yahoo.fr (I.M.B.); Tel.: +40-723-009-928 (I.M.B.)

\section{check for} updates

Citation: Ciortea, V.M.; Motoașcă, I.; Ungur, R.A.; Borda, I.M.; Ciubean, A.D.; Irsay, L. Telerehabilitation-A Viable Option for the Recovery of Post-Stroke Patients. Appl. Sci. 2021, 11, 10116. https://doi.org/10.3390/ app112110116

Academic Editors: Elena Amaricai, Lotte N. S. Andreasen Struijk, Roxana Miclaus, Oana Suciu and Roxana Onofrei

Received: 18 August 2021

Accepted: 26 October 2021

Published: 28 October 2021

Publisher's Note: MDPI stays neutral with regard to jurisdictional claims in published maps and institutional affiliations.

Copyright: (c) 2021 by the authors. Licensee MDPI, Basel, Switzerland. This article is an open access article distributed under the terms and conditions of the Creative Commons Attribution (CC BY) license (https:// creativecommons.org/licenses/by/ $4.0 /)$.

\begin{abstract}
As the number of stroke survivors is continuously growing, with an important number suffering from consequent functional deficits, the rehabilitation field is facing more complex demands. Technological progress gives us the opportunity to remotely assist patients while they exercise at home through telerehabilitation (TR), addressing the problems of limited medical resources and staff, difficult transportation, or living a long distance from rehabilitation centers. In addition, TR is a way to provide continuity in long-term post-stroke recovery during the COVID-19 pandemic, which limits traveling and human interaction. While the implementation of TR is increasing, the biggest challenges are to raise patients' acceptability of the new method and their motivation and engagement during the program. In this review, we aimed to find methods to address these challenges by identifying the patients who benefit the most from this therapy and efficiently organizing the space and technology used for telerehabilitation. User-friendly technologies and devices along with therapists' constant support and feedback are some of the most important aspects that make TR an efficient intervention and an alternative to conventional therapy.
\end{abstract}

Keywords: telerehabilitation; post-stroke recovery; robotic therapy; virtual reality; serious games

\section{Introduction}

Strokes are a frequent condition affecting 15 million people every year, of which 5 million survivors live with a consequent disability [1,2]. Healthcare and medical technologies have rapidly evolved in the last years, increasing the survival rate after stroke and therefore raising the number of patients with infirmities [3,4]. Post-stroke patients usually suffer from impaired motor function of one or more limbs, diminished sense of touch, cognition or swallowing alterations and speech and language difficulties [5]. Motor deficit of one of the upper limbs, present in about $80 \%$ of patients, is one of the most frequent consequences of stroke, and produces a dire need of rehabilitation therapy [6,7]. Loss of upper limb functionality severely impacts patients' quality of life [6,8]. The average time hospitalized post-stroke patients spend training their upper limbs is insufficient for total function recovery [7,9]. As a result of short hospitalizations and limited human resources available for face-to-face rehabilitation therapy, the majority of stroke survivors are discharged with functional deficits and are in need of continuous recovery treatment $[6,10]$. Statistics show that an important number of patients do not take part in rehabilitation programs after the acute phase of a stroke [11]. It is considered that the best time to work with the neuroplasticity and deficit recovery ability is within the first 6 months after a stroke [10,12]. However, there is evidence that also supports an intense recovery program during the chronic phase of the disease [6,12]. Thereby, post-stroke rehabilitation has an important role when applied in any stage of the disease, with its absence having consequences such 
as pathological motor pattern development, non-use of the affected limb, spasticity enhancement, joint rigidity, increased pain and disability [12-14]. In addition, rehabilitation programs initiated in the clinic and continued at patients' homes represent a therapeutic alternative to hepatotoxic and nephrotoxic medications administered to relieve pain and trophic effects $[15,16]$.

Rehabilitation therapy has proven its efficacy when task-oriented and applied in large doses, intensively, with many repetitions and continuously, in order to facilitate relearning $[7,12,17]$. The results seem to be directly proportional to the training period $[7,17]$. For example, improvements of arm function have been obtained after sessions summing $3 \mathrm{~h}$ or more per week [10]. Traditional exercises provided for patients upon discharge in order to be practiced at home have low adherence because of motivation loss, lack of pleasure while exercising and tasks that are either too hard or too easy [9]. Stroke rehabilitation represents a complex field that brings together physiotherapy, occupational therapy, speech and language therapy and neuropsychology [10]. As a result of the high costs of individual therapy sessions provided by a specialist, this is not the standard approach to chronic post-stroke patients.

Teletherapy represents an alternative in the form of a variety of communication technologies, robotic devices or computer games used at home under the remote guidance of the therapist, and is a promising option that can stimulate motivation and prevent boredom [6,8]. Telerehabilitation (TR) implies access anytime and anywhere, through the Internet and technology, to qualitative rehabilitation services of any kind: physiotherapy, occupational therapy, speech and language therapy and neuropsychology [3]. It allows patients to have continuity in the rehabilitation of their acute or chronic conditions in cases of shortage of healthcare staff and medical resources, difficult transport, living in rural areas with difficult access to rehabilitation centers or mobility and interpersonal contact restrictions in the case of a pandemic [18].

The purpose of this literature review was to identify in the literature the main challenges that may be faced when trying to initiate post-stroke telerehabilitation with the help of technology, and to contribute to the decision-making process in this emerging field. According to this, the secondary objectives were represented by: identifying patient categories who may benefit from telerehabilitation, the optimal organization of the patient's domestic space, the suitable choice of TR devices taking into account the patient's needs, the organizational needs of the therapist's workspace, ways of increasing the patient's motivation and adherence to treatment and innovative methods in TR.

\section{Search Strategy and Article Selection}

We searched the PubMed, ScienceDirect, Web of Science, Scopus and Cochrane Library databases in June 2021 using the following keywords: stroke, telerehabilitation, the Boolean operator "AND" and the publication time frame 2009-2021. Only full-text articles written in English were consulted. The search produced a total of 978 results. We removed the duplicates, the articles that had no full-text availability and the ones that were not written in English. We excluded letters, protocols, abstracts of unpublished studies, conference papers and case reports, as well as the studies that had no clear objectives or those that solely studied the efficacy of the interventions. The inclusion criteria were: written in English, full-text available, involving post-stroke patients with subsequent disabilities, intervention through telerehabilitation, overcoming or discussing the challenges of TR implementation. The articles were consulted in full-text, together with their references when clarifications were needed. A total of 46 publications were selected.

\section{Who Can Benefit from TR?}

Many studies (Table 1) have assessed the efficacy of TR on different deficits in chronic stroke and the most agreed-upon conclusion was that there is no inferiority in comparison with usual care on patient autonomy, activities of daily living and motor function $[5,11,19,20]$. However, there are no clear recommendations made in this field because 
of the heterogeneity of existing data. Therefore, more studies are needed in order to have a complete image of the most suitable ways to use TR in stroke rehabilitation.

Table 1. Patients with various disabilities who can benefit from TR.

\begin{tabular}{|c|c|c|c|}
\hline & Studies & Exercises & Results \\
\hline Hemiparesis/upper limb & $\begin{array}{l}\text { most studies, diverse } \\
\text { methodology }[21-23] ; \\
\text { reviews }[5,7,14,23,24]\end{array}$ & $\begin{array}{l}\text { Constraint-induced movement } \\
\text { therapy (CIMT) [25-27]; } \\
\text { heterogeneous exercises [21-23]; } \\
\text { biofeedback [17] }\end{array}$ & $\begin{array}{l}\text { comparable with } \\
\text { face-to-face therapy }\end{array}$ \\
\hline Hemiparesis/lower limb & $\begin{array}{l}\text { few studies; } \\
\text { not represented } \\
\text { primary objective; } \\
\text { reviews }[5,23]\end{array}$ & heterogeneous exercises & $\begin{array}{c}\text { favorable telerehabilitation } \\
\text { results; } \\
\text { low costs }\end{array}$ \\
\hline Aphasia & $\begin{array}{l}\text { comparative studies [28]; } \\
\text { randomized controlled } \\
\text { trials [29-32] }\end{array}$ & various interventions & controversial results \\
\hline $\begin{array}{l}\text { Gait disorder } \\
\text { Balance }\end{array}$ & $\begin{array}{l}\text { few studies and } \\
\text { reviews }[5,24,33]\end{array}$ & $\begin{array}{l}\text { gait exercises; } \\
\text { exercises for improving balance }\end{array}$ & $\begin{array}{c}\text { favorable results } \\
\text { assessment: Berg balance } \\
\text { scale, time up and go test, } \\
\text { modified Falls efficacy scale, } \\
\text { motricity Index }\end{array}$ \\
\hline $\begin{array}{l}\text { Psycho-emotional and } \\
\text { cognitive disorders }\end{array}$ & $\begin{array}{l}\text { secondary objectives; } \\
\text { few studies and } \\
\text { reviews }[5,22,24,32]\end{array}$ & $\begin{array}{l}\text { cognitive therapy [32]; } \\
\text { diverse therapy }\end{array}$ & $\begin{array}{l}\text { improvements in depression } \\
\text { and cognition [22]; } \\
\text { cognitive function [24]; } \\
\text { functional communication [5] }\end{array}$ \\
\hline
\end{tabular}

Using TR could make it possible to discharge patients from rehabilitation clinics after they have become accustomed to the therapeutic exercises and provide continuity of treatment by using telecommunication technology [5]. In this way, we appreciate that the chances to lose the improvements gained during hospitalization are reduced and the patients can benefit from a guided rehabilitation process in the comfort of their homes. Research suggests that the less motivated patients, those with a low degree of autonomy, and those who have difficulties using technology benefit more from in-person therapy, while highly motivated patients, and patients accustomed to the internet and different devices benefit most from TR because they can exercise as long as they want to, without the time restrictions of face-to-face training or in-clinic programs [6].

\section{How to Organize TR at Patient's Home?}

Telerehabilitation can use virtual reality technology, and regarding post-stroke patients, a rigorous assessment is needed before therapy onset. The evaluation is essential for therapy settings and outcome establishment. It requires at least a few sessions of exergames to be performed by the patient before home training, so they can be familiarized with virtual reality technology. It is essential for patients to learn from the physiotherapist how to correctly perform the exercises as a complement to the virtual assistance provided by the technology used [34,35].

An important aspect and challenge of the implementation of TR is the spatial planning of a patient's home where the training will take place. The risk of fall or injury during exercise has to be reduced to a minimum and redressing support in case of balance loss or standing up after a fall has to be assured [36]. Probably due to safety procedures, some studies found balance to be one of the outcomes where TR did not prove its efficacy [11]; however, there are some research results that suggest the opposite [33,37]. Therefore, when the exercises performed at home target walking and balance, it is of importance to ensure the safety of therapy sessions with the presence of a family member or another informal caregiver who can supervise, support and help the patient in case of loss of balance (Figure 1). Moreover, the family member can help in establishing the communication with 
the rehabilitation team. The exercising room has to be spacious enough in order to maintain a minimum of $2 \mathrm{~m}$ between the patient and the surrounding furniture during the entire time of walking and balance training.

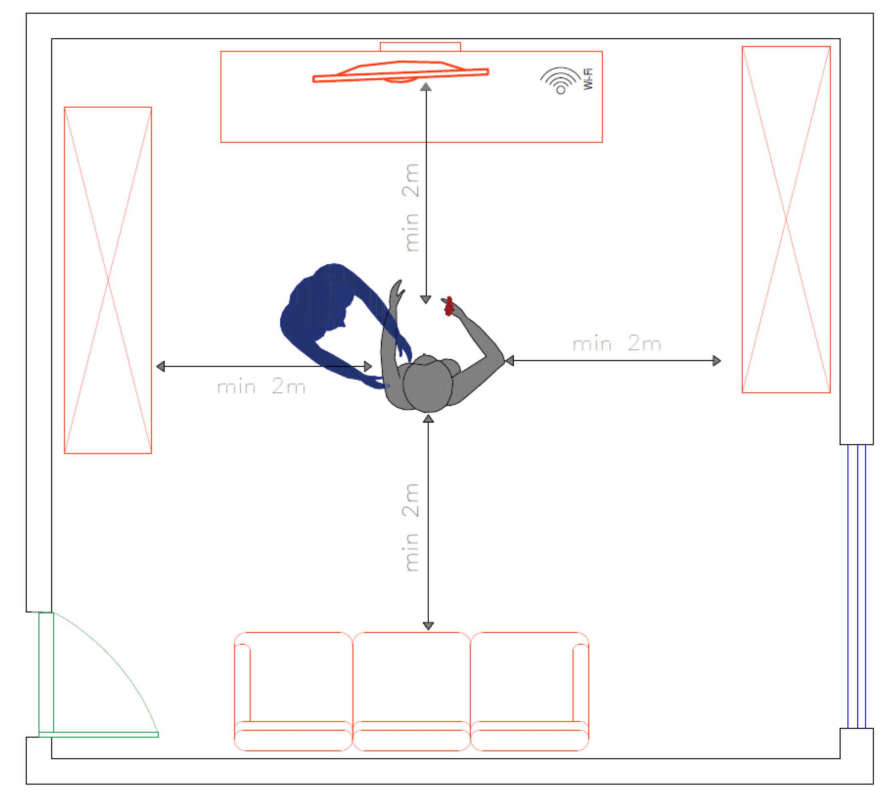

Figure 1. Safe space for TR practice at home.

\section{How Can Technology Contribute to Rehabilitation Progress?}

Nowadays, there is a continuous growth in the number of people of all ages that use communication technologies, the majority having at least a mobile phone if not also a tablet or a computer [4]. Health professionals often make incorrect assumptions about patients' interest and abilities regarding TR, especially when it comes to the elderly, cognitively impaired patients, people coming from underprivileged environments or those with financial problems. These assumptions have frequently been misleading as these patients managed to conform to and involve themselves in TR [36]. One study showed that for the older population, the most reliable way to deliver telemedicine was through a mobile phone, which was probably the most accessible and easy to use kind of all devices [1]. However, multiple types of devices were used during TR, most of them being already present in patients' homes or easily acquirable (Figure 2).

One of the most used ways to replace traditional exercises that take place in a physiotherapy room is through serious games. These games are designed to target functionality and performance in order to accomplish their purpose of enhancing the user's various skills [19]. Moreover, when developing such games for rehabilitation, the programmer, by respecting the relearning process and constant feedback necessities [19], may create an intelligent application that can be in some cases a better substitute of human guidance because the equipment such as video camera and sensors can become flawless assessors and tireless helpers. Furthermore, the permanent online storage of acquired data permits previously written algorithms to process and analyze information based on current experience [13]. The programmed artificial intelligence being able to analyze hundreds of data inputs from multiple sources at the same time could provide the specialist with a quicker and more informed therapy solution.

Besides the patient-side technical equipment and training space, a special workspace for the therapist has to be set up (Figure 3). The minimal equipment needed by the therapist for TR coordination is a data server, a computer, a tablet or a telephone, camera, headphones, a stable internet connection and a private workspace [36]. 




Figure 2. Devices used for TR at the patient's home.

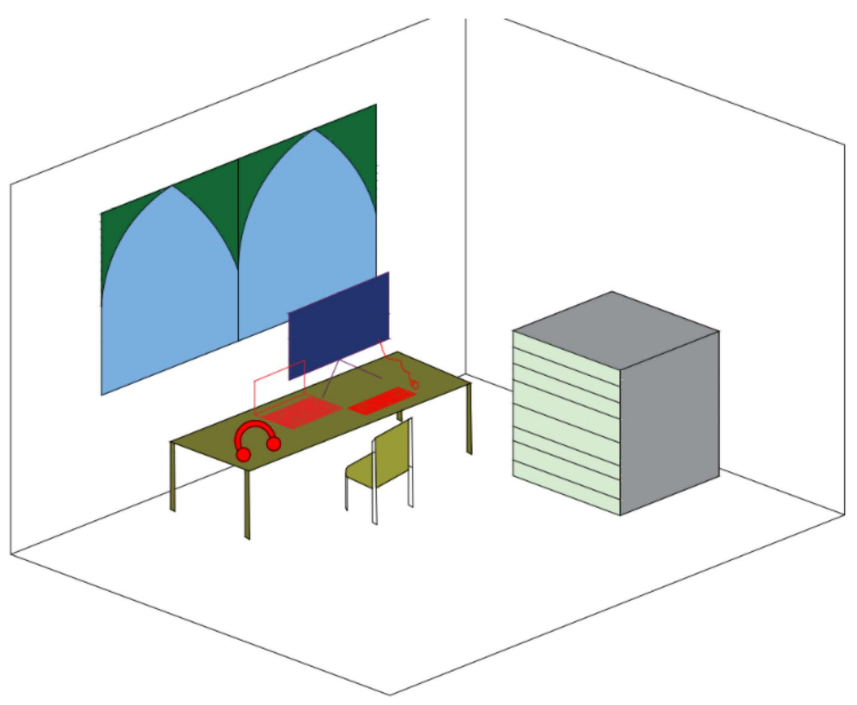

Figure 3. Therapist's private workspace and data server room.

One issue that has to be addressed when it comes to TR is data security and network safety during data transfer from patients' devices to the local server and to the clinician's workstation [5]. Therefore, it is appropriate to work together with an IT professional for the development, administration and support of the entire data system in order to assure security, reliability, data integrity and redundancy of both server-side and clientside applications. Special measures should be taken in order to assure the security of patients' personal and clinical data by regularly testing the system infrastructure and the data storage center for security flaws (Figure 4). 




Figure 4. TR network setup.

TR has the potential to contribute to the standardization of rehabilitation services and to offer objective monitoring with long-term data storage and follow-up $[4,36]$.

\section{Telerehabilitation during COVID-19}

Efficient ways to substitute hands-on physical examinations and physiotherapy have to be found by making use of novel technology, robots, sensors or informal caregivers [5]. Rozevink et al. adapted their study protocol [6] during the COVID-19 pandemic in order to be able to measure impaired arm functionality after the intervention and to comply with the prevention of SARS-CoV-2 transmission. They delivered the needed equipment to every patient and, together with a family member, made a video call. During the call, with the help of the caregiver, they performed the tests and completed the final evaluation and study protocol.

During the COVID-19 pandemic, a significant decline was observed in cases in stroke units [38] and post-stroke patients referred to rehabilitation clinics [39]. The causes were the reluctance to visit the emergency department, various medical system limitations, patients' will to avoid prolonged contact with the health system or family reluctant to accommodate the visiting restrictions imposed by the epidemiological situation [39]. The fact that neurorehabilitation was not of high priority during the pandemic in order to decrease the overload of the medical system negatively impacted stroke patients and responsible health professionals [13,40]. Medical resources were preferentially concentrated in treating COVID-19 patients. The number of beds available in rehabilitation clinics was drastically decreased in order to assure social distancing, patients with COVID-like symptoms were not eligible for any rehabilitation treatment, some rehabilitation activities were temporarily stopped and patients were prematurely discharged for epidemiological reasons [36].

Telemedicine is probably the medical field with the most rapid and complex development during the COVID-19 pandemic. For many health services, it became a necessity in order to maintain social distancing and decrease the risk of viral transmission while meeting the constant demands of healthcare [40-42]. During the COVID-19 pandemic, telerehabilitation is a solution to continue the recovery of post-stroke patients without the consumption of protective equipment, while limiting viral transmission risk in a group that is already vulnerable [43,44].

Lately, TR implementation has been performed in a stressful period and has been a challenge for the health professionals without experience. Previous contact with telemedicine, a well-prepared IT department and management involvement have made TR implementation easier [36].

Assenza et al. explored patients' and professionals' perception of a TR intervention during COVID-19 lockdown through questionnaires. Remotely delivered therapy was 
introduced in order to substitute traditional rehabilitation during the period of travel restrictions and social distancing requirements. Patients received it with a high level of skepticism and low adherence. Healthcare professionals also had a moderate level of trust in the benefits of TR and reported the lack of physical contact as an important limitation to their work. However, rehabilitation specialists with previous experience with remotely delivered therapy trusted its efficacy more than those without experience [41]. These results make it clear that TR is a field that needs more practiced and trained medical personnel to manage the implementation of any level of this new therapy option.

\section{The Acceptability, Accessibility and Usability of Telerehabilitation}

Some patients may consider TR inferior to conventional face-to-face rehabilitation and be reluctant to accept it [11,41]. Being, for many, a new approach, researchers were confronted with skepticism from patients and their families, while therapists have the mission to persuade users about the new concept and its advantages [36].

In order to accept different new technologies as part of their recovery process, patients need to trust their therapist and be open to novelty. The presence of fear that the devices are too fragile and that they may get damaged during exercises can decrease acceptability for patients unfamiliar with technology [9]. The teletherapy system should fulfill some basic requirements such as assuring user safety, being user-friendly, not needing frequent technical maintenance, and requiring minimal home reorganization and investment [13].

One study based on questionnaires distributed to patients, caregivers and healthcare professionals found that the possibility of using the e-rehabilitation program on different devices (phone, tablet and computer) was considered positively for accessibility. Another preference of patients and caregivers was small and easy to use devices [45]. Researchers also noted the patients' preference for the application interface. The most suitable interface is a calm interface without bright, fast-moving images [9]. The existence of user support in any form was also stated as being a priority [45], including in the transition period from conventional therapy to the new therapy [9]. Another identified factor that counted for the acceptance of rehabilitation through technology was the way the devices fit into patients' homes [9].

Teletherapy solves the problem of transportation and has few restraints on location and time of performance, therefore improving accessibility of rehabilitation services [12].

\section{Engagement and Motivation in Telerehabilitation}

Patients' perception of TR is generally good, with positive satisfaction reports [11]. Keeping the post-stroke patient engaged and motivated through the rehabilitation process seems to be one of the most challenging parts of telerehabilitation [6]. The lack of compliance with the therapy protocol can reach $70 \%$ of cases when the training is performed at home without direct supervision [12]. Many factors such as a small variety of games or exercises, poor structure of the intervention, too challenging or too easy tasks, the lack of feedback or poor-quality feedback can negatively affect patients' motivation [9]. Therefore, when it comes to telerehabilitation, it seems that the focus should not only be on high-performance technology, but also on therapists who should be ready to adapt and modify the therapy and handle a disengaged, demotivated, frustrated or bored patient. The communication skills of therapists may be challenged in different ways from situations encountered during face-to-face rehabilitation, and their training in this field may be opportune. One study showed that the system used for TR motivated the patient if it reported their real-time progress to the therapist and permitted the latter's prompt and regular intervention [17]. Another benefit of the patient's constant contact with a therapist has been the improvement of the social isolation feeling and overall mood [12]. The absence of a social network and human interaction represents a risk factor for stroke recurrence, its presence being associated with better clinical progress during TR due to socially offered support and motivation [2]. The consistency of post-stroke patients' treatment depends 
on the integration of the training in their daily routine, and for this, shorter trainings with a higher frequency were preferred [9].

During our literature review, we identified a variety of reasons that explained the cases of low compliance with TR that specialists faced. The most frequent are: an elderly population with no experience with technology or reluctance to it, lack of time for exercise at home, absence of a caregiver to provide assistance during training, lack of specialist supervision, cognitive impairments after stroke and bad internet connection. Therefore, one important aspect is the thorough selection of patients with additional attention given to aspects that may lead to low compliance.

\section{Innovation in Telerehabilitation}

Numerous technologies and devices were recently developed in order to assist rehabilitation in hospital setting or at home [46]. In Table 2, we list the technologies that successfully addressed the challenges of TR by trying to minimize its shortcomings compared with face-to-face rehabilitation.

The continuous feedback of the therapist during in-clinic training of a spastic limb is missing during classical home training. The visual information provided by EMG or sensor assessment helps the patient to perform the movements correctly and efficiently while also increasing their motivation $[6,17,47]$.

The stimulation of the sense of touch, usually done by the therapist during in-person sessions by touching the patient at key moments in order to rectify, explain or encourage patient's movement, is also missing during teletherapy, and patients perceive this as a limitation. Handelzalts et al. addressed this limitation by using vibrations generated by a wearable device [44].

Aphasia can accompany acute stroke symptoms in $20-40 \%$ of cases, and although there is an important number of patients that recover due to early neuroplasticity, speech impairment remains one of the challenges of chronic stroke rehabilitation [48]. It has a significant impact on patient's life, contributes to social isolation, makes communication with family and caregivers harder, increases disease $=$ related frustration and represents an important factor in depression onset [49]. Speech and language therapy, the traditional techniques used in the management of aphasic patients, is meant to restore the communication abilities of post-stroke patients. It is one of the conventional therapies where novel technologies such as video chat, virtual reality and computer games can be successfully implemented, and it can be included in telerehabilitation services [48,49].

Last but not least, post-stroke patients usually lack sufficient physical activity. The American Stroke Association stated that the consequences are further loss of functional capacity and increased risk of secondary complications. Furthermore, there is scientific evidence which sustains aerobic exercise for improving cardiorespiratory fitness after stroke in order to obtain important benefits in both physical and psychosocial health [50]. Continuous home cardiorespiratory training was addressed through TR by Galloway et al. [51]. 
Table 2. Technology for TR delivery.

\begin{tabular}{|c|c|c|c|c|c|}
\hline & & Innovative Technology & Principle & Advantages & \\
\hline \multirow{2}{*}{$\begin{array}{l}1 \\
2\end{array}$} & \multirow{2}{*}{ 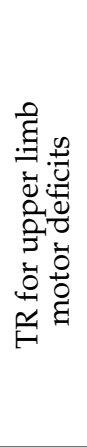 } & $\begin{array}{c}\text { Visual muscle biofeedback } \\
\text { through EMG during } \\
\text { serious games }\end{array}$ & $\begin{array}{l}\text { real-time continuous } \\
\text { feedback of agonist and } \\
\text { antagonist muscle } \\
\text { contraction during } \\
\text { exercises }\end{array}$ & $\begin{array}{l}\text { training of muscle control, } \\
\text { strength and arm function } \\
\text { while focusing on wrist } \\
\text { extensor muscle activity } \\
\text { and limiting wrist flexor } \\
\text { unwitting contraction }\end{array}$ & [17] \\
\hline & & $\begin{array}{l}\text { Robotic device with } \\
\text { forearm support and } \\
\text { sensors to detect active } \\
\text { movements (angles, force) }\end{array}$ & $\begin{array}{l}\text { specific software that } \\
\text { generates serious games } \\
\text { and real-time } \\
\text { visualization of the } \\
\text { movements on a tablet }\end{array}$ & $\begin{array}{l}\text { feedback offered to the } \\
\text { patient to bring more } \\
\text { motivation through the } \\
\text { process }\end{array}$ & {$[6,47]$} \\
\hline 3 & 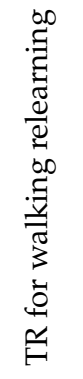 & $\begin{array}{l}\text { Vibration signals applied } \\
\text { through a wearable device } \\
\text { as a substitute for the } \\
\text { therapist's tactile feedback }\end{array}$ & $\begin{array}{l}\text { enhanced feedback that } \\
\text { guides the patients } \\
\text { through their training } \\
\text { without capturing their } \\
\text { visual attention }\end{array}$ & $\begin{array}{l}\text { simulation of the physical } \\
\text { contact with a therapist } \\
\text { and the sense of human } \\
\text { support and } \\
\text { encouragement of } \\
\text { importance for the } \\
\text { psychology of patients } \\
\text { during rehabilitation }\end{array}$ & [44] \\
\hline 4 & 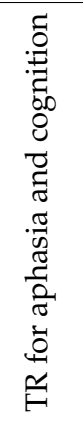 & $\begin{array}{l}\text { Tablet with integrated } \\
\text { virtual reality system } \\
\text { remotely controlled }\end{array}$ & $\begin{array}{l}\text { memory, attention, } \\
\text { perception, speech } \\
\text { abilities, language, global } \\
\text { cognitive functions and } \\
\text { executive functions } \\
\text { trained through } \\
\text { personalized exercises }\end{array}$ & $\begin{array}{l}\text { big variety of interactive } \\
\text { exercises available, } \\
\text { adapted by the therapist } \\
\text { in terms of duration and } \\
\text { difficulty to the level of } \\
\text { impairment each patient } \\
\text { presents; better than } \\
\text { paper-pencil exercises; } \\
\text { decrease in anxiety levels }\end{array}$ & {$[49,52]$} \\
\hline 5 & 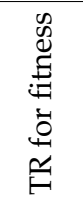 & $\begin{array}{l}\text { Aerobic exercises } \\
\text { performed at home while } \\
\text { video conferencing }\end{array}$ & $\begin{array}{c}\text { guidance and supervision } \\
\text { of a therapist during } \\
\text { training }\end{array}$ & $\begin{array}{c}\text { safe, reliable, good } \\
\text { attendance rates, } \\
\text { enjoyable and efficient }\end{array}$ & [51] \\
\hline
\end{tabular}

\section{Conclusions}

Current research in TR supports changing care protocols for chronic stroke patients by including more intensive, high dose therapy in the form of TR for patients that easily adapt to new technology, and conventional rehabilitation for less motivated patients [6].

Due to the heterogeneity of the existing research methodology and to the wide variety of technology and systems used in telerehabilitation research, we are in agreement with our colleagues Laver et al. [5] and Appleby et al. [11] that no firm recommendations can be made regarding the use of TR in clinical practice at this time. More experience should be gained regarding technology and device efficacy, the best time and dose of TR delivery, and healthcare professional training in this field, with emphasis on the proper approach and guidance of patients.

Because there is growing interest in the telerehabilitation field, with clinics already providing this kind of services [5], systematic research is necessary in order to fill the knowledge gaps in this area and to develop practical recommendations and strategies. 
Author Contributions: Conceptualization, V.M.C., I.M.B. and I.M.; methodology, all; resources, all; writing-original draft preparation, V.M.C.; writing—review and editing, V.M.C., R.A.U., L.I. and I.M.; visualization, A.D.C., L.I. and I.M.; supervision, V.M.C., L.I., I.M.B. and R.A.U. All authors have read and agreed to the published version of the manuscript.

Funding: This research received no external funding.

Institutional Review Board Statement: Not applicable.

Informed Consent Statement: Not applicable.

Data Availability Statement: No new data were created or analyzed in this study. Data sharing is not applicable to this article.

Conflicts of Interest: The authors declare they have no conflict of interest.

\section{References}

1. Moradi, V.; Babaee, T.; Esfandiari, E.; Lim, S.B.; Kordi, R. Telework and telerehabilitation programs for workers with a stroke during the COVID-19 pandemic: A commentary. World 2021, 68, 77-80.

2. Podury, A.; Raefsky, S.M.; Dodakian, L.; McCafferty, L.; Le, V.; McKenzie, A.; See, J.; Zhou, R.J.; Nguyen, T.; Wong, G.; et al. Social Network Structure Is Related to Functional Improvement From Home-Based Telerehabilitation After Stroke. Front. Neurol. 2021, 12, 603767. [CrossRef] [PubMed]

3. Miao, M.; Gao, X.; Zhu, W. A Construction Method of Lower Limb Rehabilitation Robot with Remote Control System. Appl. Sci. 2021, 11, 867. [CrossRef]

4. Marwaa, M.N.; Kristensen, H.K.; Guidetti, S.; Ytterberg, C. Physiotherapists' and occupational therapists' perspectives on information and communication technology in stroke rehabilitation. PLoS ONE 2020, 15, e0236831. [CrossRef] [PubMed]

5. Laver, K.E.; Adey-Wakeling, Z.; Crotty, M.; Lannin, N.A.; George, S.; Sherrington, C.; Cochrane Database of Systematic Reviews. Telerehabilitation Services for Stroke. 2020. Available online: https://www.cochranelibrary.com/cdsr/doi/10.1002/14651858 .CD010255.pub3/full (accessed on 5 June 2021).

6. Rozevink, S.G.; Van der Sluis, C.K.; Garzo, A.; Keller, T.; Hijmans, J.M. HoMEcare aRm rehabiLItatioN (MERLIN): Telerehabilitation using an unactuated device based on serious games improves the upper limb function in chronic stroke. J. Neuro. Eng. Rehabil. 2021, 18, 48. [CrossRef]

7. Cramer, S.C.; Dodakian, L.; Le, V.; See, J.; Augsburger, R.; McKenzie, A.; Zhou, R.J.; Chiu, N.L.; Heckhausen, J.; Cassidy, J.M.; et al. Efficacy of Home-Based Telerehabilitation vs In-Clinic Therapy for Adults After Stroke: A Randomized Clinical Trial. JAMA Neurol. 2019, 76, 1079. [CrossRef] [PubMed]

8. Cramer, S.C.; Dodakian, L.; Le, V.; McKenzie, A.; See, J.; Augsburger, R.; Zhou, R.J.; Raefsky, S.M.; Nguyen, T.; Wong, G.; et al. A Feasibility Study of Expanded Home-Based Telerehabilitation After Stroke. Front. Neurol. 2021, 11, 611453. [CrossRef]

9. Neibling, B.A.; Jackson, S.M.; Hayward, K.S.; Barker, R.N. Perseverance with technology-facilitated home-based upper limb practice after stroke: A systematic mixed studies review. J. Neuro. Eng. Rehabil. 2021, 18, 43. [CrossRef]

10. Platz, T. Clinical Pathways in Stroke Rehabilitation: Evidence-Based Clinical Practice Recommendations; Springer International Publishing: Cham, Switzerland, 2021. Available online: http:/ /link.springer.com/10.1007/978-3-030-58505-1 (accessed on 5 June 2021).

11. Appleby, E.; Gill, S.T.; Hayes, L.K.; Walker, T.L.; Walsh, M.; Kumar, S. Effectiveness of telerehabilitation in the management of adults with stroke: A systematic review. PLoS ONE 2019, 14, e225150. [CrossRef]

12. Ostrowska, P.M.; Śliwiński, M.; Studnicki, R.; Hansdorfer-Korzon, R. Telerehabilitation of Post-Stroke Patients as a Therapeutic Solution in the Era of the Covid-19 Pandemic. Healthcare 2021, 9, 654. [CrossRef] [PubMed]

13. Lambercy, O.; Lehner, R.; Chua, K.; Wee, S.K.; Rajeswaran, D.K.; Kuah, C.W.K.; Ang, W.T.; Liang, P.; Campolo, D.; Hussain, A.; et al. Neurorehabilitation From a Distance: Can Intelligent Technology Support Decentralized Access to Quality Therapy? Front. Robot AI 2021, 8, 612415. [CrossRef]

14. Amorim, P.; Sousa Santos, B.; Dias, P.; Silva, S.; Martins, H. Serious Games for Stroke Telerehabilitation of Upper Limb-A Review for Future Research. Int. J. Telerehab. 2020, 12, 65-76. [CrossRef] [PubMed]

15. Irsay, L.; Checiches, A.; Perja, D.; Borda, I.M.; Dogaru, G.; Onac, I. Pharmacological pain management in patients with chronic kidney disease. Balneo 2019, 10, 12-16. [CrossRef]

16. Irsay, L.; Checiches, A.; Perja, D.; Borda, I.M.; Dogaru, G.; Ungur, R.; Ciubean, A.; Ciortea, V. Pharmacological pain management in patients with chronic hepatic disease. Balneo 2019, 10, 119-123. [CrossRef]

17. Marin-Pardo, O.; Phanord, C.; Donnelly, M.R.; Laine, C.M.; Liew, S.-L. Development of a Low-Cost, Modular Muscle-Computer Interface for At-Home Telerehabilitation for Chronic Stroke. Sensors 2021, 21, 1806. [CrossRef]

18. Irsay, L.; Ciubean, A. Telemedicine and Ocupational Therapy. In Ocupational Therapy; “Iuliu Hatieganu” University Medical Publisher: Cluj-Napoca, Romania, 2020; pp. 196-199.

19. Doumas, I.; Everard, G.; Dehem, S.; Lejeune, T. Serious games for upper limb rehabilitation after stroke: A meta-analysis. J. Neuro. Eng. Rehabil. 2021, 18, 100. [CrossRef] [PubMed] 
20. Tenforde, A.S.; Zafonte, R.; Hefner, J.; Iaccarino, M.A.; Silver, J.; Paganoni, S. Evidence-Based Physiatry: Efficacy of Home-Based Telerehabilitation Versus In-Clinic Therapy for Adults After Stroke. Am. J. Phys. Med. Rehabil. 2020, 99, 764-765. [CrossRef]

21. Piron, L.; Turolla, A.; Agostini, M.; Zucconi, C.; Cortese, F.; Zampolini, M.; Zaninni, M.; Dam, M.; Ventura, L.; Battauz, M.; et al. Exercises for paretic upper limb after stroke: A combined virtual-reality and telemedicine approach. J. Rehabil. Med. 2009, 41, 1016-1020. [CrossRef] [PubMed]

22. Burdea, G.C.; Grampurohit, N.; Kim, N.; Polistico, K.; Kadaru, A.; Pollack, S.; Oh-Park, M.; Barrett, A.M.; Kaplan, E.; Masmela, J.; et al. Feasibility of integrative games and novel therapeutic game controller for telerehabilitation of individuals chronic post-stroke living in the community. Top Stroke Rehabil. 2020, 27, 321-336. [CrossRef]

23. Saywell, N.; Vandal, A.C.; Brown, P.; Hanger, H.C.; Hale, L.; Mudge, S.; Milosavljevic, S.; Feigin, V.; Taylor, D. Telerehabilitation to improve outcomes for people with stroke: Study protocol for a randomised controlled trial. Trials 2012, 13, 233. [CrossRef]

24. Laver, K.E.; Lange, B.; George, S.; Deutsch, J.E.; Saposnik, G.; Crotty, M. Virtual reality for stroke rehabilitation. Cochrane Database Syst. Rev. 2017, 11, CD008349. [CrossRef]

25. Gauthier, L.V.; Kane, C.; Borstad, A.; Strahl, N.; Uswatte, G.; Taub, E.; Morris, D.; Hall, A.; Arakelian, M.; Mark, V. Video Game Rehabilitation for Outpatient Stroke (VIGoROUS): Protocol for a multi-center comparative effectiveness trial of in-home gamified constraint-induced movement therapy for rehabilitation of chronic upper extremity hemiparesis. BMC Neurol. 2017, 17, 109. [CrossRef] [PubMed]

26. Uswatte, G.; Taub, E.; Lum, P.; Brennan, D.; Barman, J.; Bowman, M.H.; Taylor, A.; McKay, A.; Sloman, S.B.; Morris, D.M.; et al. Tele-rehabilitation of upper-extremity hemiparesis after stroke: Proof-of-concept randomized controlled trial of in-home constraint-induced movement therapy. Restor. Neurol. Neurosci. 2021, 39, 303-318, preprint.

27. Smith, M.A.; Tomita, M.R. Combined effects of Telehealth and Modified Constraint-Induced Movement Therapy for Individuals with Chronic Hemiparesis. Int. J. Telerehabil. 2020, 12, 51-62. [CrossRef]

28. Keidel, M.; Vauth, F.; Richter, J.; Hoffmann, B.; Soda, H.; Griewing, B.; Scibor, M. Home-based telerehabilitation after stroke. Nervenarzt 2017, 88, 113-119. [CrossRef]

29. Uslu, A.S.; Gerber, S.M.; Schmidt, N.; Röthlisberger, C.; Wyss, P.; Vanbellingen, T.; Schaller, S.; Wyss, C.; Koenig-Bruhin, M.; Berger, T.; et al. Investigating a new tablet-based telerehabilitation app in patients with aphasia: A randomised, controlled, evaluator-blinded, multicentre trial protocol. BMJ Open 2020, 10, e037702. [CrossRef]

30. Øra, H.P.; Kirmess, M.; Brady, M.C.; Winsnes, I.E.; Hansen, S.M.; Becker, F. Telerehabilitation for aphasia-protocol of a pragmatic, exploratory, pilot randomized controlled trial. Trials 2018, 19, 208. [CrossRef]

31. Peñaloza, C.; Scimeca, M.; Gaona, A.; Carpenter, E.; Mukadam, N.; Gray, T.; Shampant, S.; Kiran, S. Telerehabilitation for Word Retrieval Deficits in Bilinguals With Aphasia: Effectiveness and Reliability as Compared to In-person Language Therapy. Front. Neurol. 2021, 12, 589330. [CrossRef]

32. Braley, M.; Pierce, J.S.; Saxena, S.; De Oliveira, E.; Taraboanta, L.; Anantha, V.; Lakhan, S.E.; Kiran, S. A Virtual, Randomized, Control Trial of a Digital Therapeutic for Speech, Language, and Cognitive Intervention in Post-stroke Persons With Aphasia. Front. Neurol. 2021, 12, 626780. [CrossRef]

33. Chen, S.-C.; Lin, C.-H.; Su, S.-W.; Chang, Y.-T.; Lai, C.-H. Feasibility and effect of interactive telerehabilitation on balance in individuals with chronic stroke: A pilot study. J. Neuro. Eng. Rehabil. 2021, 18, 71. [CrossRef]

34. Miclaus, R.S.; Roman, N.; Henter, R.; Caloian, S. Lower Extremity Rehabilitation in Patients with Post-Stroke Sequelae through Virtual Reality Associated with Mirror Therapy. Int. J. Environ. Res. Public Health 2021, 18, 2654. [CrossRef]

35. Miclaus, R.; Roman, N.; Caloian, S.; Mitoiu, B.; Suciu, O.; Onofrei, R.R.; Pavel, E.; Neculau, A. Non-Immersive Virtual Reality for Post-Stroke Upper Extremity Rehabilitation: A Small Cohort Randomized Trial. Brain Sci. 2020, 10, 655. [CrossRef]

36. Signal, N.; Martin, T.; Leys, A.; Maloney, R.; Bright, F. Implementation of telerehabilitation in response to COVID-19: Lessons learnt from neurorehabilitation clinical practice and education. N. Z. J. Physiother. 2020, 48, 117-126.

37. Burgos, P.I.; Lara, O.; Lavado, A.; Rojas-Sepúlveda, I.; Delgado, C.; Bravo, E.; Kamisato, C.; Torres, J.; Castañeda, V.; Cerda, M. Exergames and Telerehabilitation on Smartphones to Improve Balance in Stroke Patients. Brain Sci. 2020, 10, 773. [CrossRef]

38. Digital Technologies, Web and Social Media Study Group of the Italian Society of Neurology; Iodice, F.; Romoli, M.; Giometto, B.; Clerico, M.; Tedeschi, G.; Bonavita, S.; Leocani, L.; Lavorgna, L. Stroke and digital technology: A wake-up call from COVID-19 pandemic. Neurol. Sci. 2021, 42, 805-809. [CrossRef]

39. Thau, L.; Siegal, T.; Heslin, M.E.; Rana, A.; Yu, S.; Kamen, S.; Chen, A.; Vigilante, N.; Gallagher, S.; Wegner, K.; et al. Decline in Rehab Transfers Among Rehab-Eligible Stroke Patients During the COVID-19 Pandemic. J. Stroke Cerebrovasc. Dis. 2021, 30, 105857. [CrossRef]

40. Atashzar, S.F.; Carriere, J.; Tavakoli, M. Review: How Can Intelligent Robots and Smart Mechatronic Modules Facilitate Remote Assessment, Assistance, and Rehabilitation for Isolated Adults With Neuro-Musculoskeletal Conditions? Front. Robot AI 2021, 8, 610529. [CrossRef]

41. Assenza, C.; Catania, H.; Antenore, C.; Gobbetti, T.; Gentili, P.; Paolucci, S.; Morelli, D. Continuity of Care During COVID-19 Lockdown: A Survey on Stakeholders' Experience With Telerehabilitation. Front. Neurol. 2021, 11, 617276. [CrossRef]

42. Chang, M.C.; Boudier-Revéret, M. Usefulness of Telerehabilitation for Stroke Patients During the COVID-19 Pandemic. Am. J. Phys. Med. Rehabil. 2020, 99, 582. [CrossRef] 
43. Guzik, A.K.; Martin-Schild, S.; Tadi, P.; Chapman, S.N.; Al Kasab, S.; Martini, S.R.; Meyer, B.M.; Demaerschalk, B.M.; Woznaik, M.A.; Southerland, A.M. Telestroke Across the Continuum of Care: Lessons from the COVID-19 Pandemic. J. Stroke Cerebrovasc. Dis. 2021, 30, 105802. [CrossRef] [PubMed]

44. Handelzalts, S.; Ballardini, G.; Avraham, C.; Pagano, M.; Casadio, M.; Nisky, I. Integrating Tactile Feedback Technologies Into Home-Based Telerehabilitation: Opportunities and Challenges in Light of COVID-19 Pandemic. Front. Neurorobot. 2021, 15, 617636. [CrossRef] [PubMed]

45. Wentink, M.M.; Bodegom-Vos, L.; van Brouns, B.; Arwert, H.J.; Vliet Vlieland, T.P.M.; De Kloet, A.J.; Meesters, J.J. What is Important in E-health Interventions for Stroke Rehabilitation? A Survey Study among Patients, Informal Caregivers, and Health Professionals. Int. J. Telerehab. 2018, 10, 15-28. [CrossRef] [PubMed]

46. Choukou, M.-A.; Mbabaali, S.; Bani Hani, J.; Cooke, C. Haptic-Enabled Hand Rehabilitation in Stroke Patients: A Scoping Review. Appl. Sci. 2021, 11, 3712. [CrossRef]

47. Guillén-Climent, S.; Garzo, A.; Muñoz-Alcaraz, M.N.; Casado-Adam, P.; Arcas-Ruiz-Ruano, J.; Mejías-Ruiz, M.; MayordomoReira, F.J. A usability study in patients with stroke using MERLIN, a robotic system based on serious games for upper limb rehabilitation in the home setting. J. Neuro. Eng. Rehabil. 2021, 18, 41. [CrossRef]

48. De Cock, E.; Batens, K.; Feiken, J.; Hemelsoet, D.; Oostra, K.; De Herdt, V. The feasibility, usability and acceptability of a tablet-based aphasia therapy in the acute phase following stroke. J. Commun. Disord. 2021, 89, 106070. [CrossRef]

49. Maresca, G.; Maggio, M.G.; Latella, D.; Cannavò, A.; De Cola, M.C.; Portaro, S.; Stagnitti, M.C.; Silvestri, G.; Torissi, M.; Bramanti, A.; et al. Toward Improving Poststroke Aphasia: A Pilot Study on the Growing Use of Telerehabilitation for the Continuity of Care. J. Stroke Cerebrovasc. Dis. 2019, 28, 104303. [CrossRef] [PubMed]

50. Winstein, C.J.; Stein, J.; Arena, R.; Bates, B.; Cherney, L.R.; Cramer, S.C.; Deruyter, F.; Eng, J.J.; Fisher, B.; Harvey, R.L.; et al. Guidelines for Adult Stroke Rehabilitation and Recovery: A Guideline for Healthcare Professionals From the American Heart Association/American Stroke Association. Stroke 2016, 47, e98-e169. Available online: https:/ /www.ahajournals.org/doi/10.116 1/STR.0000000000000098 (accessed on 5 June 2021). [CrossRef]

51. Galloway, M.; Marsden, D.L.; Callister, R.; Nilsson, M.; Erickson, K.I.; English, C. The Feasibility of a Telehealth Exercise Program Aimed at Increasing Cardiorespiratory Fitness for People After Stroke. Int. J. Telerehab. 2019, 11, 9-28. [CrossRef]

52. Torrisi, M.; Maresca, G.; De Cola, M.C.; Cannavò, A.; Sciarrone, F.; Silvestri, G.; Bramanti, A.; De Luca, R.; Calabrò Salvatore, R. Using telerehabilitation to improve cognitive function in post-stroke survivors: Is this the time for the continuity of care? Int. J. Rehabil. Res. 2019, 42, 344-351. [CrossRef] 